\title{
A mathematical model
}

\section{On the effect of growth hormone on glucose homeostasis}

\author{
Hannah AlAli* — Wiam Boutayeb** - Abdesslam Boutayeb* — Nora Merabet* \\ * School of Mathematics, Statistics \& Computing \\ Emirates Aviation University \\ Dubai \\ United Arab Emirates \\ \{hannah.alali, nora.merabet\}@emirates.com, Abdesslam.Boutayeb@eau.ac.ae, \\ ** Department of Mathematics, Faculty of Sciences \\ Mohammed $1^{\text {st }}$ University, \\ Oujda \\ Morocco \\ wiam.boutayeb@gmail.com
}

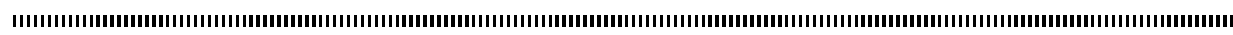

RÉSUMÉ. Prolongeant un précédent model publié dédié à l'interaction entre les cellules $\beta$, l'insuline, le glucose, les recepteurs d'insuline et les acides gras libres, cet article propose un modele mathématique introduisant l'effet de l'hormone de croissance sur l'homéostasie du glucose. L'analyse de stabilité a été suivie d'explication pratique des points d'équilibre. Enfin, la simulation a illustré comment les cellules $\beta$, l'insuline, le glucose, les récepteurs d'insuline, les acides gras libres et l'hormone de croissance peuvent varier en fonction des différentes valeurs de certains paramètres.
\end{abstract}

ABSTRACT. Extending an existing model devoted to the interaction between $\beta$-cell mass, insulin, glucose, receptor dynamics and free fatty acids, in glucose regulatory system simulation, this paper proposes a mathematical model introducing the effect of growth hormone on the glucose homeostasis alongside the other variables. Stability analysis is carried out and pragmatic explanation of the equilibrium points is emphasized. Finally, simulation illustrated how $\beta$-cell mass, insulin, glucose, receptor dynamics, free fatty acids and growth hormone may vary with different values of some parameters in the model.

MOTS-CLÉS : Modèle, Equilibre, Stabilité, Simulation, Cellules $\beta$, Insuline, Glucose, Recepteurs d'insuline, Acides gras libres, Hormone de croissance.

KEYWORDS : Model, Equilibrium, Stability, Simulation, $\beta$-Cell Mass, Insulin, Glucose, Receptor, Free Fatty Acids, Growth Hormone

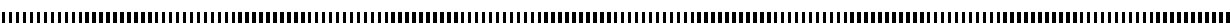




\section{Introduction}

During the last decades, an important number of publications were devoted to mathematical modeling applied to diabetes. We cite in particular, the papers presenting a model of $\beta$-Cell Mass, Insulin, and Glucose Kinetics [17], mathematical modeling and simulation of $\beta$-Cell Mass, Insulin, and Glucose dynamics: effect of genetic predisposition to diabetes [4], dynamic modeling of Free Fatty Acids, Glucose, and Insulin: an extended minimal model [14], a model of $\beta$-Cell Mass, Insulin, Glucose and Receptor Dynamics [8] and the impact of obesity on predisposed people to type 2 diabetes: a mathematical model of $\beta$-Cell Mass, Insulin, Glucose, Receptor Dynamics and Free Fatty Acids [5]. For more publications on modeling for diabetes, we refer to the following reviews [1]-[3], [6], [11]-[13] and [15]. In this paper, we consider the effect of Growth Hormone (GH) on glucose homeostasis, extending the previous model published by Boutayeb W et al. [5]. While growth hormone is well known to promote growth in children by acting on a number of tissues and organs, it is importance for adults is less known. It doesn't cause growth in adults but it plays a major role in metabolism, muscle mass function, lipid control and glucose homeostasis. The idea of investigating growth hormone was mainly motivated by a review article published by Kim S-H and Park M-J in 2017 on the effects of growth hormone $(\mathrm{GH})$ on glucose metabolism and insulin resistance in human [9]. The review article summarized the main findings of several studies on this subject as follows:

1) Investigating the effects of growth hormone $(\mathrm{GH})$ on glucose metabolism have demonstrated that $\mathrm{GH}$ increases glucose production through gluconeogenesis and glycogenolysis from the liver and kidney.

2) Growth hormone stimulates lipolysis which results in free fatty acid (FFA) flux from adipose tissue to circulation.

3) Increased FFA in circulation can induce insulin resistance. Meanwhile, increase in FFA uptake by hepatocytes results in promotion of hepatic lipid oxidation and accumulation of Acetyl-CoA, yielding an increase of blood glucose levels.

4) Interaction between insulin and $\mathrm{GH}$ downstream of receptor activation in the skeletal muscle and adipose tissue provides another alternative mechanism mediating GHinduced resistance.

Consequently, growth hormone can be introduced in a mathematical model besides other hormones and factors like glucose, insulin, beta-cells, insulin receptors and free fatty acids (FFA). 


\section{The mathematical model}

Our model is an extension of the model of Boutayeb et al. [5] which involves five variables (glucose, insulin, $\beta$-cell mass, insulin receptors and free fatty acids) governed by the five following nonlinear differential equations :

$$
\begin{array}{rc}
\frac{d \beta}{d t} & =\left(-g+h G(t)-i G(t)^{2}\right) \beta(t) \\
\frac{d I}{d t} & =\frac{\beta d G^{2}}{(1+R)\left(e+G^{2}\right)}-f I-f R I \\
\frac{d G}{d t} & =a-(b+c R I) G+m_{1}\left(F-F_{b}\right) \\
\frac{d R}{d t} & =j(1-R)-k I R-l R \\
\frac{d F}{d t} & =-m_{2}\left(F-F_{b}\right)+m_{3}\left(G-G_{b}\right)
\end{array}
$$

where $\beta$-cell mass $\beta(t)$, insulin $I(t)$, glucose $G(t)$, insulin receptors $R(t)$ and growth hormone $G H(t)$ are all functions of time, from which $t$ was omitted for simplicity. All the coefficient parameters, their interpretation and values are recalled in Table 1.

\begin{tabular}{c|l|l|l}
\hline Parameter & Value & Units & Biological Interpretation \\
\hline $\mathrm{a}$ & 864 & $\frac{m g}{d l d}$ & glucose production rate by liver when $G=0$ \\
$\mathrm{~b}$ & 1.44 & $d^{-1}$ & glucose clearance rate independent of insulin \\
$\mathrm{c}$ & 0.85 & $\frac{m l}{\mu U d}$ & insulin induced glucose uptake rate \\
$\mathrm{d}$ & 43.2 & $\frac{\mu u}{m l d m g}$ & $\beta$-cell maximum insulin secretory rate \\
$\mathrm{e}$ & 20,000 & $\frac{m g^{2}}{d l^{2}}$ & gives inflection point of sigmoidal function \\
$\mathrm{f}$ & 216 & $d^{-1}$ & whole body insulin clearance rate \\
$\mathrm{j}$ & 2.64 & $d^{-1}$ & insulin receptor recycling rate \\
$\mathrm{k}$ & 0.02 & $\frac{m l}{\mu U d}$ & insulin dependent receptor endocytosis rate \\
$\mathrm{l}$ & 0.24 & $d^{-1}$ & insulin independent receptor endocytosis rate \\
$\mathrm{g}$ & 0.03 & $d^{-1}$ & $\beta$-cell natural death rate \\
$\mathrm{h}$ & $0.5727 \mathrm{e}-3$ & $\frac{d l}{m g d}$ & determines $\beta$-cell glucose tolerance range \\
$\mathrm{i}$ & $0.2523 \mathrm{e}-5$ & $\frac{d l^{2}}{m g^{2} d}$ & determines $\beta$-cell glucose tolerance range \\
$m_{1}$ & 0.0864 & $\frac{1}{d \mu m o l}$ & constant rate \\
$m_{2}$ & 43.2 & $d^{-1}$ & constant rate for FFA production \\
$m_{3}$ & 97.92 & $\frac{m l^{-1}}{\text { constant rate for Glucose production }}$ \\
$F_{b}$ & 11 & $\frac{m g}{d l}$ & basal value of Free Fatty Acids \\
$G_{b}$ & 98 & $\frac{m g}{d l}$ & basal value of glucose \\
\hline
\end{tabular}

Table 1. Parameters in Insulin, Glucose, FFA, $\beta$ cells \& Receptors equations used by [5] 
In our model, we add growth hormone dynamics, by including a sixth differential equation for $G H(t)$ and by exhibiting the interaction of $G H$ with glucose and FFA as follows:

$$
\begin{aligned}
\frac{d \beta}{d t} & =\left(-g+h G(t)-i G(t)^{2}\right) \beta(t) \\
\frac{d I}{d t} & =\frac{\beta d G^{2}}{(1+R)\left(e+G^{2}\right)}-f I-f R I \\
\frac{d G}{d t} & =a-(b+c R I) G+m_{1}\left(F-F_{b}\right)+c G H \\
\frac{d R}{d t} & =j(1-R)-k I R-l R \\
\frac{d F}{d t} & =-m_{2}\left(F-F_{b}\right)+m_{3}\left(G-G_{b}\right)+x\left(G H-G H_{b}\right) \\
\frac{d G H}{d t} & =p-w G H-s\left(F-F_{b}\right)-z R
\end{aligned}
$$

From equation (11), the rate of the growth hormone $G H$ is increased by the rate of production of $G H$ by the somatotropic cells $(p)$, occurring in the pituitary gland. It is decreased by the rate of $G H$ clearance/absorption by the liver $(w)$, the rate of uptake of $G H$ by Fat cells ( $s$ ) and by the rate of uptake of $G H$ by receptor cells $(z)$. Growth hormone also increases the rate of glucose $(c)$ as well as the rate of FFA $(x)$. Parameters (and their values) used in the $G H$ equation are given in Table 2 below. Other nonlinear and more complicated interactions of $G H$ with $\beta$-cells, insulin and receptors will be addressed in further future research work.

\begin{tabular}{c|l|l|l}
\hline$G H$ Coefficients in equations & Value & Units & Biological Interpretation \\
\hline$p$ & 363 & $\frac{m l \mu g}{m i n}$ & GH production rate by somatotropic cells \\
$w$ & 136 & $\frac{m l}{m i n}$ & GH clearance rate by the liver \\
$s$ & 0.1 & $\frac{n g l}{d m l \mu m o l}$ & rate of uptake of GH by Fat cells \\
$z$ & 2 & $\frac{n g l}{d m l}$ & rate of uptake of GH by receptor cells \\
$x$ & 200 & $\frac{m l \mu m o l}{l d n g}$ & constant rate for GH production \\
$G H_{b}$ & 5 & $\frac{n g}{m l}$ & basal value of growth hormone \\
\hline
\end{tabular}

Table 2. Parameters and their values used in the growth hormone equation [16] 


\section{Stability analysis}

\subsection{Equilibrium points}

The equilibrium points satisfy:

$$
\frac{d \beta}{d t}=\frac{d I}{d t}=\frac{d G}{d t}=\frac{d R}{d t}=\frac{d F}{d t}=\frac{d G H}{d t}=0
$$

From equations (6) \& (12) :
either
(a) $\beta=\beta_{0}^{*}=0, \quad$ or
(b) $-g+h G-i G^{2}=0$

Case $(\mathbf{a})$ : By direct substitution of $\beta=0$ into equations of insulin and receptors (7) \& (9), we get three values:

$$
\beta=\beta_{0}^{*}=0, \quad I=I_{0}^{*}=0, \quad R=R_{0}^{*}=\frac{j}{j+l}
$$

Substituting these values, into the original system gives the algebraic expressions for $G_{0}^{*}, F_{0}^{*}, G H_{0}^{*}$ as solutions to the following linear system

$$
\left(\begin{array}{ccc}
b & -m_{1} & -c \\
0 & s & w \\
m_{3} & -m_{2} & x
\end{array}\right)\left(\begin{array}{c}
G \\
F \\
G H
\end{array}\right)=\left(\begin{array}{c}
a-m_{1} F_{b} \\
p+s F_{b}-z \frac{j}{j+l} \\
m_{3} G_{b}-m_{2} F_{b}+x G H_{b}
\end{array}\right)
$$

with

$$
\begin{aligned}
G H_{0}^{*} & =\frac{\gamma}{\theta} \\
F_{0}^{*} & =-\frac{w}{s} G H_{0}^{*}+\frac{1}{s}\left(p+s F_{b}-z \frac{j}{j+l}\right) \\
G_{0}^{*} & =\frac{a-m_{1} F_{b}+m_{1} F_{0}^{*}+c G H_{0}^{*}}{b}
\end{aligned}
$$

such that $\theta$ and $\gamma$ are given by

$$
\begin{gathered}
\theta=s\left(x b+c m_{3}\right)-w\left(m_{1} m_{3}-m_{2} b\right) . \\
\gamma=s b\left(m_{3} G_{b}+x G H_{b}-m_{2} F_{b}\right)-s m_{3}\left(a-m_{1} F_{b}\right)-\left(m_{1} m_{3}-m_{2} b\right)\left(p+s F_{b}-z \frac{j}{j+l}\right) .
\end{gathered}
$$

Hence, a first equilibrium point is

$$
P_{0}=\left(\beta_{0}^{*}, I_{0}^{*}, G_{0}^{*}, R_{0}^{*}, F_{0}^{*}, G H_{0}^{*}\right)=\left(0,0, G_{0}^{*}, \frac{j}{j+l}, F_{0}^{*}, G H_{0}^{*}\right)
$$

in which $G_{0}^{*}, F_{0}^{*}$ and $G H_{0}^{*}$ are respectively given by (15), (16) and (17). 
Case $(\mathbf{b}):\left(-g+h G-i G^{2}\right)=0$ has two roots

$$
G_{1}^{*}=\frac{h+\sqrt{h^{2}-4 i g}}{2 i}
$$

and $G_{2}^{*}=\frac{h-\sqrt{h^{2}-4 i g}}{2 i}$ Taking $G=G_{n}^{*}(n=1,2)$ and considering

$$
\frac{d R}{d t}=\frac{d G}{d t}=\frac{d G H}{d t}=\frac{d F}{d t}=0
$$

yields the following nonlinear system:

$$
\begin{aligned}
j(1-R)-k R I-l R & =0 \\
b G_{n}^{*}-m_{1} F-c G H+c R I G_{n}^{*} & =a-m_{1} F_{b} \\
s F+w G H+z R & =p+s F_{b} \\
-m_{2} F+x G H & =-m_{3}\left(G_{n}^{*}-G_{b}\right)-m_{2} F_{b}+x G H_{b}
\end{aligned}
$$

The nonlinearity term $R I$ in $\frac{d G}{d t}$, is then replaced by $R I=\frac{j}{k}-\frac{j+l}{k} R$, derived from $\frac{d R}{d t}=0$ and the system is re-arranged as a linear system of three unknowns $F, G H$ and $R$, as follows :

$$
\left(\begin{array}{ccc}
m_{1} & c & \delta \\
m_{2} & -x & 0 \\
s & w & z
\end{array}\right)\left(\begin{array}{c}
F \\
G H \\
R
\end{array}\right)=\left(\begin{array}{l}
\alpha \\
\lambda \\
\mu
\end{array}\right)
$$

Where:

$$
\begin{gathered}
\delta=\frac{c(j+l)}{k} G_{n}^{*}, \quad \alpha=\frac{c j}{k} G_{n}^{*}+b G_{n}^{*}-a+m_{1} F_{b}, \\
\lambda=m_{3}\left(G_{n}^{*}-G_{b}\right)+m_{2} F_{b}-x G H_{b}, \quad \mu=p+s F_{b} .
\end{gathered}
$$

The solution of this system is given by:

$$
\begin{aligned}
R_{n}^{*} & =\frac{\left(\mu m_{1}-\alpha s\right)\left(x m_{1}+c m_{2}\right)+\left(w m_{1}-c s\right)\left(\lambda m_{1}-\alpha m_{2}\right)}{\left(x m_{1}+c m_{2}\right)\left(z m_{1}-\delta s\right)-\delta m_{2}\left(w m_{1}-c s\right)} \\
G H_{n}^{*} & =\frac{\left(\alpha m_{2}-\lambda m_{1}\right)}{\left(x m_{1}+c m_{2}\right)}-\frac{\delta m_{2}}{\left(x m_{1}+c m_{2}\right)} R_{n}^{*} \\
F_{n}^{*} & =\frac{\alpha}{m_{1}}-\frac{\delta}{m_{1}} R_{n}^{*}-\frac{c}{m_{1}} G H_{n}^{*}
\end{aligned}
$$


then, expressions for $I_{n}^{*}$ and $\beta_{n}^{*}$ follow from substitutions and are given by:

$$
\begin{aligned}
I_{n}^{*} & =\frac{j}{k} \frac{1}{R_{n}^{*}}-\frac{j+l}{k} \\
\beta_{n}^{*} & =\frac{f I_{n}^{*}+f I_{n}^{*} R_{n}^{*}}{d} \frac{\left(1+R_{n}^{*}\right)\left(e+G_{n}^{* 2}\right)}{G_{n}^{* 2}}
\end{aligned}
$$

Consequently, the second and third equilibrium points $P_{n}, n=1,2$ are given by:

$$
P_{n}=\left(\beta_{n}^{*}, I_{n}^{*}, G_{n}^{*}, R_{n}^{*}, F_{n}^{*}, G H_{n}^{*}\right), \quad n=1,2
$$

using equations (19) to (23).

\subsection{Stability Analysis}

The Jacobian of the system is given by:

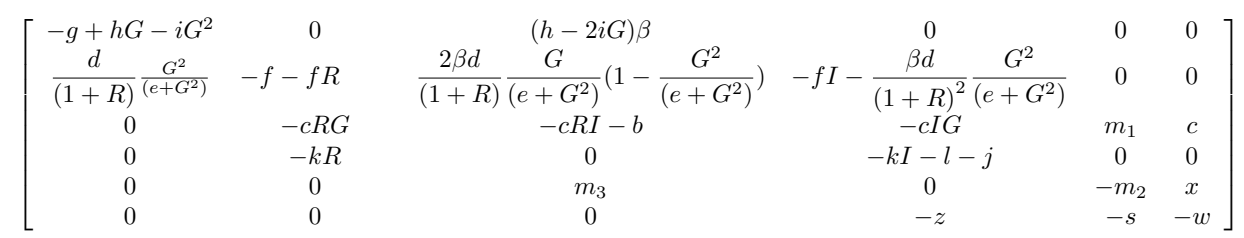

Using parameters' values listed in Tables 1 and 2, we evaluate the Jacobian at each equilibrium point $P_{0}, P_{1}$ and $P_{2}$ given by equations (18) and (24). Then eigenvalues of resulting matrices $J\left(P_{n}\right)$, for $n=0,1,2$ are computed to classify the equilibrium points, as follows: The eigenvalues of the Jacobian $J\left(P_{0}\right)$ at $P_{0}$ are :

$$
-1.24,-44.16,-69.23,-2.88,-412.56,-0.81
$$

All the eigenvalues of the Jacobian $J\left(P_{0}\right)$ are negative, hence $P_{0}$ is a stable pathological point which indicates that a diabetic person with a complete apoptosis of $\beta$-cells is in a state of no return. In this case treatment of diabetes must be by exogenous injection of insulin. The eigenvalues of the Jacobian $J\left(P_{1}\right)$ at $P_{1}$ are :

$$
-383,-44.42,-24.64,-2.88,-69.23,-0.005
$$

Similarly, all the eigenvalues of the Jacobian $J\left(P_{1}\right)$ are negative, hence $P_{1}$ is a stable physiological point. In opposition to the previous case, here stability means that a person having values of the six variables in the required physiological range will remain in a healthy state as far as the values vary within the vicinity of the healthy ranges. The eigenvalues of the Jacobian $J\left(P_{2}\right)$ at $P_{2}$ are :

$$
-401,-69,-44,-10.26,0.1,-2.88
$$


In the case of $P_{2}$, one of the eigenvalues is not negative and hence, this equilibrium point is a saddle point, which means, that a person living with these values of the six variables may evolve towards a physiological or a pathological state.

\subsection{Classification and interpretation of equilibrium points}

Using the parameter values given in Tables 1 and 2 yields equilibrium points with numerical values as follows:

$$
\text { (a) } P_{0}\{\beta=0, I=0, G=680, R=.92, F=1681, G H=1.7\} \text {, }
$$

This equilibrium point is considered as a pathological equilibrium point in which insulin and $\beta$-cell mass are equal to zero and consequently a very high value of glucose $(680 \mathrm{mg} / \mathrm{dl})$ occurs, indicating a dangerous hyperglycemia as it happens in people with type1 diabetes at a late diagnosis. This pathological point is also associated with a high level of FFA $(1681 \mu \mathrm{mol} / \mathrm{l})$ and a relatively low value of GH $(1.7 \mathrm{ng} / \mathrm{ml})$ which is in agreement with known biological statements since, under physiological conditions, high levels of glucose and FFA inhibits secretion of growth hormone [7].

$$
\text { (b) } P_{1}\{\beta=855, I=12.67, G=82, R=.84, F=333, G H=2.7\}
$$

This second equilibrium point is considered as a physiological equilibrium point in which all the variables have usual average physiological values. Indeed, it shows that glucose $(82 \mathrm{mg} / \mathrm{dl})$ is in the range of a no diabetic person, the $\beta$-cells are functioning normally and consequently, insulin is also in the physiological range $\left(12.74 \frac{\mu U}{m l}\right)$. Similarly, free fatty acids and growth hormone correspond to a normal physiological state.

$$
\text { (c) } P_{2}\{\beta=211.6, I=6.14, G=145, R=.88, F=475, G H=2.6\}
$$

The third equilibrium point is between the physiological and the pathological states. It indicates low values of $\beta$-cell mass $(211 \mathrm{mg})$ and insulin $\left(6.14 \frac{\mu U}{\mathrm{ml}}\right)$ and consequently a value of glucose $(145 \mathrm{mg} / \mathrm{dl})$ exceeding the threshold needed for a no diabetic person. Free fatty acids appear also to be higher while the level of GH is in the acceptable range. This intermediate equilibrium point is practically interesting since it implies three possibilities of evolution:

- Evolution towards the pathological point if apoptosis of $\beta$-cells is continued until the death of all cells, yielding zero insulin production.

- Evolution towards the physiological point if apoptosis of $\beta$-cells is stopped and eventually reversed in such a way to increase production of insulin. This could be the case of obese people doing no physical activity and eating unhealthy diet who change their behavior completely to do physical activity, loose weight and eat healthy diet.

- No evolution or small perturbations around high levels of glucose and FFA, and low levels of insulin and $\beta$-cells. 
Variation in concentrations of $\beta$ cells, insulin, glucose, receptors, FFA and growth hormone is illustrated by the Figure below.

NOTE. - In the physiological state (in case of no diabetes), reference values for $\beta$-cells mass, insulin, glucose, FFA and growth hormone fall within the following ranges:

$\beta$-cell mass $=850 \mathrm{mg}, I=10 \mu \mathrm{U} / \mathrm{ml}, G=100 \mathrm{mg} / \mathrm{dl}$ (FFA) $F=380 \mu \mathrm{mol} / \mathrm{ml}$, Growth hormone: $G H<5 \mathrm{ng} / \mathrm{ml}$ for men and $G H<10 \mathrm{ng} / \mathrm{ml}$ for women.
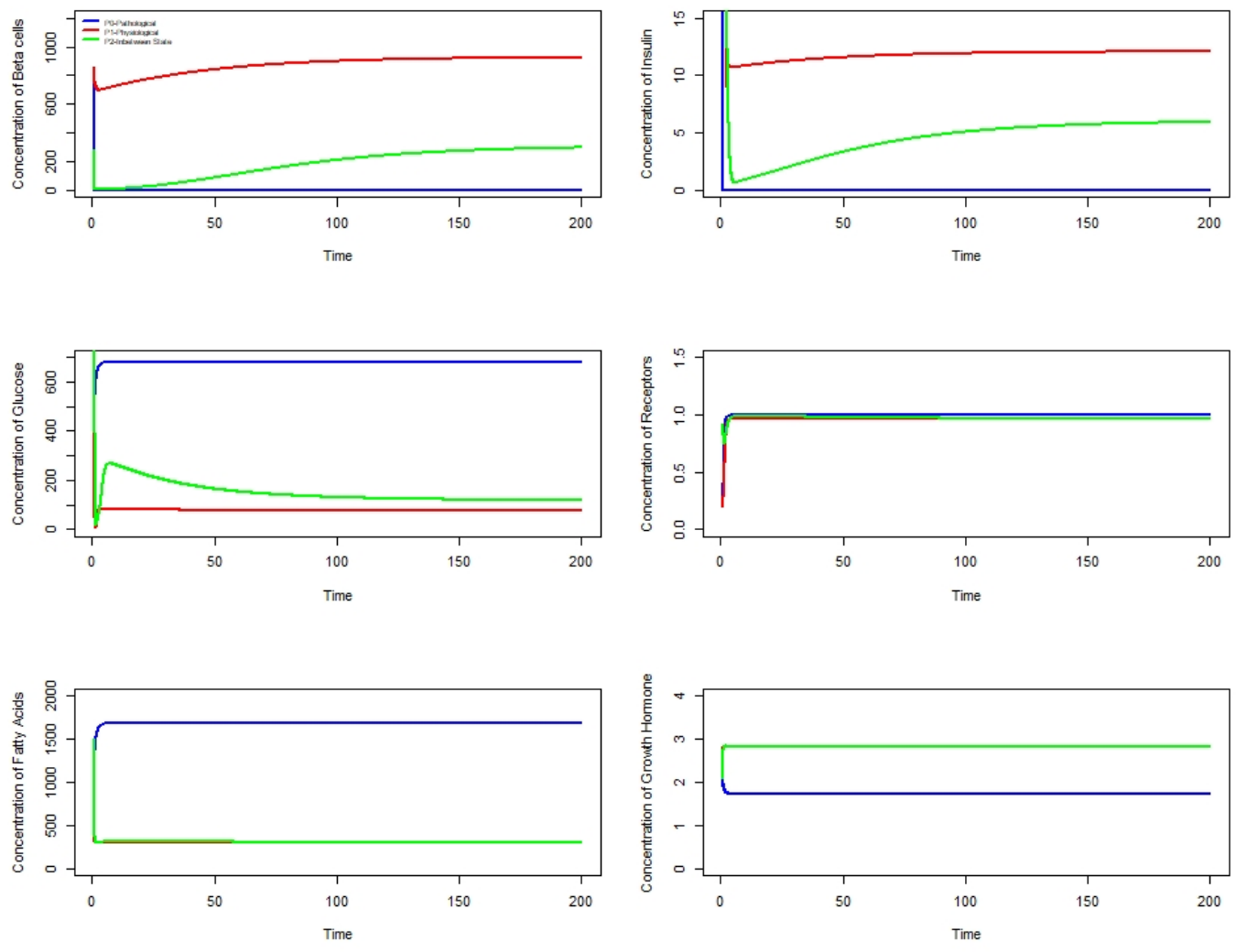

Figure 1. Concentrations of $\beta$ cells, insulin, glucose, receptors, FFA and growth hormone 


\section{Simulation}

\subsection{Insulin sensitivity (c)}

Studies have shown that on the one hand, physical exercise can increase insulin sensitivity by $36 \%$ and on the other hand, insulin resistance due to obesity and/or other factors can decrease insulin induced glucose uptake by $50 \%$ to $100 \%$ [4], [8], and [17]. Following this, a simulation was carried out with different values of the parameter $c$ to check how the intermediate equilibrium point $P_{2}$ may vary. It was found that variation of $c$ does not affect glucose, insulin receptors, FFA nor $G H$ but it affects $\beta$-cells mass and insulin as indicated in Table 3.

\begin{tabular}{c|c|c}
\hline$c$-value & $\beta$-cell mass & Insulin \\
\hline 1 & 180 & 5.19 \\
0.85 & 212 & 6.14 \\
0.42 & 429 & 12.98 \\
\hline
\end{tabular}

Table 3. Variation of $\beta$-cell mass and insulin with respect to $c$-values

\subsection{Production of $G H$ by the somatotropic cells ( $p$ )}

Simulation with different values of the parameter $p$ have shown that, in the intermediate equilibrium point $P_{2}$, values of $\beta$-cell mass, Insulin, Glucose, Insulin Receptors are not affected while FFA and $G H$ increase with increased values of $p$ as indicated in Table 4

\begin{tabular}{c|c|c}
\hline$p$-value & FFA & Growth hormone \\
\hline 363 & 475.4 & 2.59 \\
400 & 476.6 & 2.86 \\
600 & 483.4 & 4.32 \\
900 & 493.6 & 6.52 \\
\hline
\end{tabular}

Table 4. Variation of FFA and growth hormone with respect to $p$-values

\subsection{Growth Hormone clearance / absorption by the liver $(w)$}

Simulation with different values of the parameter w have shown that, in the intermediate equilibrium point, values of $\beta$-cell mass, Insulin, Glucose, Insulin Receptors are not affected while FFA and GH decrease with increased $w$ as indicated in Table 5. 


\begin{tabular}{c|c|c}
\hline$w$-value & FAA & Growth hormone \\
\hline 20 & 543.2 & 17.25 \\
80 & 483.7 & 4.39 \\
300 & 468.8 & 1.17 \\
136 & 475.4 & 2.59 \\
\hline
\end{tabular}

Table 5. Variation of FFA and growth hormone with respect to $w$-values

\section{Conclusion}

While there is an abundant literature on mathematical models dealing with glucose dynamics in interaction with insulin, very few models are devoted to the effect of growth hormone on glucose homeostasis. To our knowledge, this paper is the first to introduce the combined interaction between the variables glucose, insulin, free fatty acids (FFA) and growth hormone. Local stability analysis showed that, beside the stable pathological and stable physiological equilibrium points, there is a saddle point with levels of $\beta$-cells mass and insulin lower than the corresponding values required in the physiological case. The unstable point indicates also a value of glucose higher than the value needed in a nondiabetic person. Pragmatically, this intermediate equilibrium point refers to a prediabetic stage and our mathematical model indicates that evolution towards diabetes may be avoided or at least delayed provided efficient action on risk factors like obesity/overweight, unhealthy diet, physical inactivity and smoking. Simulations using different values of parameters illustrated the importance of insulin sensitivity and how to avoid insulin resistance caused mainly by weight excess and lack of physical activity. The rates of production and clearance (and eventually deficiency) of growth hormone were also used to simulate variation of free fatty acids and growth hormone.

\section{Bibliography}

[1] Ajmera I., Swat M., Laibe C., Le Novere N., Chelliah V. « The impact of mathematical modeling on the understanding of diabetes and related complications », CPT: pharmacometrics \& systems pharmacology, Wiley Online Library, vol. 2, $\mathrm{n}^{\circ}$ 7, 1-4, 2013.

[2] BALAKRishnan N., RAngaiah G., SAMAVEDHAM L., « Review and analysis of blood glucose (BG) models for type 1 diabetic patients », Industrial \& Engineering Chemistry Research, ACS Publications, vol. 50, $\mathrm{n}^{\circ}$ 21, 12041-12066, 2011.

[3] Boutayeb A., Chetounini A., « A critical review of mathematical models and data used in diabetology », Biomedical engineering online, BioMed Central, vol. 5, $\mathrm{n}^{\circ}$ 1, 43, 2006.

[4] Boutayeb W., Lamlili M., Boutayeb A., Derouich M., « Mathematical modelling and simulation of $\beta$-cell mass, insulin and glucose dynamics: Effect of genetic predisposition to 
diabetes », Journal of Biomedical Science and Engineering, Scientific Research Publishing , vol. 7, $\mathrm{n}^{\circ}$ 06, 330, 2014.

[5] Boutayeb W., Lamlili M., Boutayeb A., Derouich M., « The impact of obesity on predisposed people to type 2 diabetes: Mathematical model », International Conference on Bioinformatics and Biomedical Engineering, Springer, $\mathrm{n}^{\circ}$ 613-622, 2014.

[6] Dias Cifha C., Kamath S., Vidyasagar S., « Mathematical modelling and simulation of $\beta$-cell mass, insulin and glucose dynamics: Effect of genetic predisposition to diabetes », International Journal of Bioinformatics Research and Applications, Inderscience Publishers (IEL), vol. 4, $\mathrm{n}^{\circ} 1-2,90-103,2018$.

[7] Gunawardane K., Hansen T., Christiansen J., Jorgensen J., « Normal physiology of growth hormone in adults », MDText. com, Inc., 2015.

[8] Hernandez R., Lyles D., Rubin D., Voden T., Wirkus S., « A model of $\beta$-cell mass, insulin, glucose and receptor dynamics with applications to diabetes », Cornell Univ., Dept. of Biometrics, Technical Report BU-1579-M, 2001.

[9] KIM S., PARK M., «Effects of growth hormone on glucose metabolism and insulin resistance in human », Annals of pediatric endocrinology \& metabolism, Korean Society of Pediatric Endocrinology, vol. 22, $\mathrm{n}^{\mathrm{O}}$ 3, 145, 2017.

[10] Li JiAXU, Johnson J., « Mathematical models of subcutaneous injection of insulin analogues: a mini-review », Discrete and continuous dynamical systems. Series B, NIH Public Access, vol. 12, $\mathrm{n}^{\circ}$ 2, 401, 2009.

[11] Makroglou A., Li Jiaxu, Kuang Y., « Mathematical models and software tools for the glucose-insulin regulatory system and diabetes: an overview », Applied numerical mathematics, North-Holland, vol. 56, n ${ }^{\circ}$ 3-4, 559-573, 2006.

[12] Nucci G., Cobelli C., " Models of subcutaneous insulin kinetics. A critical review », Computer methods and programs in biomedicine, Elsevier, vol. 62, $\mathrm{n}^{\circ}$ 3, 249-257, 2000.

[13] Pattaranit R., VAn D., « Mathematical models of energy homeostasis », Journal of The Royal Society Interface, The Royal Society, vol. 5, n 27, 1119-1135, 2008.

[14] RoY, A., PARKer R., « Dynamic modeling of free fatty acid, glucose, and insulin: An extended" minimal model », Diabetes technology \& therapeutics, Mary Ann Liebert, USA, vol. 8, $\mathrm{n}^{\circ} 6,617-626,2006$.

[15] Smith J., MaAs J., Maas J., Garnsworthy P., Owen M., Coombes S., Pillay T., BARRETT D. , SYMONDS M., « Mathematical modeling of glucose homeostasis and its relationship with energy balance and body fat », Journal of Biomedical Science and Engineering, Scientific Research Publishing, Wiley Online Library, vol. 17, $\mathrm{n}^{\circ}$ 4, 632-639, 2009.

[16] TAYlor A., Mintz D., « Metabolic clearance and production rates of human growth hormones. », the Journal of Clinical Investigation, vol. 48, 2349-2358, 1969.

[17] Topp B., Promislow K., Devries G., Miura R., T Finegood D., « A model of $\beta$-cell mass, insulin, and glucose kinetics: pathways to diabetes », Journal of theoretical biology, Elsevier, vol. 206, n ${ }^{\circ}$ 4, 605-619, 2000. 